AperTO - Archivio Istituzionale Open Access dell'Università di Torino

\title{
Neuropathic Pain Management in Chronic Laminitis
}

\section{This is the author's manuscript}

Original Citation:

Availability:

This version is available http://hdl.handle.net/2318/77529

since

Terms of use:

Open Access

Anyone can freely access the full text of works made available as "Open Access". Works made available under a Creative Commons license can be used according to the terms and conditions of said license. Use of all other works requires consent of the right holder (author or publisher) if not exempted from copyright protection by the applicable law. 


\section{(x) \\ UNIVERSITÀ DEGLI STUDI DI TORINO}

This is an author version of the contribution published on:

Questa è la versione dell'autore dell'opera:

Veterinary Clinics of North America: Equine Practice

Volume 26, August 2010,

doi:10.1016/j.cveq.2010.04.002

Bernd Driessen, Sébastien H. Bauquier, Laura Zarucco,

26, Issue 2, Christopher C. Pollitt, 2010, pages 315-337

The definitive version is available at:

La versione definitiva è disponibile alla URL:

http://www.vetequine.theclinics.com 


\section{Pain (Neuropathic) Management of Chronic Laminitis}

Bernd Driessen, DVM, PhD ${ }^{\mathrm{a}, \mathrm{b}}$, Sébastien H. Bauquier, DMV ${ }^{\mathrm{c}}$ and Laura Zarucco, DMV, PhD ${ }^{\mathrm{d}}$

${ }^{a}$ Section of Emergency/Critical Care and Anesthesia, Department of Clinical Studies-New Bolton Center, School of Veterinary Medicine, University of Pennsylvania, Kennett Square, Pennsylvania

${ }^{b}$ Department of Anesthesiology, David-Geffen School of Medicine, University of CaliforniaLos Angeles, Los Angeles, California

${ }^{\mathrm{c}}$ Section of Critical Care, Department of Clinical Studies-Philadelphia, School of Veterinary Medicine, University of Pennsylvania, Philadelphia, Pennsylvania

${ }^{\mathrm{d}}$ Dipartimento di Patologia Animale, Facoltà di Medicina Veterinaria, Università degli Studi di Torino, Grugliasco, Italy

KEYWORDS: • Horse $\bullet$ Laminitis • Neuropathic Pain $\bullet$ NSAIDs $\bullet$ Analgesics $\bullet$ Gabapentin

\section{Corresponding author:}

Bernd Driessen, DVM, PhD, Dipl. ACVA, Dipl. ECVPT, Section of Emergency/Critical Care and Anesthesia, Department of Clinical Studies-New Bolton Center, School of Veterinary Medicine, University of Pennsylvania, 382 West Street Road, Kennett Square, PA 19348, USA.

Office: +1 (610) 925-6130Ｆax: +1 (610) 925-8120ｅ-mail: Driessen@,vet.upenn.edu

Co-authors' addresses:

Sébastien H. Bauquier, DVM, Section of Critical Care, Department of Clinical Studies-Philadelphia, School of Veterinary Medicine, University of Pennsylvania, 3850 Spruce Street, Philadelphia, PA 19104, USA.

Office: + 1 (267) $6390940 \quad$ e-mail: Bauquier@vet.upenn.edu

Laura Zarucco, DMV, PhD, Dipartimento di Patologia Animale, Facoltà di Medicina Veterinaria, Università degli Studi di Torino, Via Leonardo da Vinci 44, 10095 Grugliasco (TO), Italy.

Office: +39 (349) 593-0110ｅ-mail: laura.zarucco@unito.it 
Managing pain in horses afflicted by chronic laminitis is one of the greatest challenges in equine clinical practice because it is the dreadful suffering of the animals that most often forces the veterinarian to end the battle with this disease. The purpose of this review is to summarize our current understanding of the very complex mechanisms involved in generating and amplifying pain in animals with laminitis and based on this information to propose a modified approach to pain therapy. Furthermore a recently developed pain scoring technique is being presented that may help better quantify pain and the monitoring of responses to analgesic treatment in horses with laminitis.

\section{MECHANISMS OF PAIN IN LAMINITIS}

Understanding the neuroanatomy of the equine foot and pathophysiological processes involved in triggering and modifying nociception during the course of laminitis, though incompletely understood, is essential when searching for effective pain management strategies in affected animals. This applies even more if one considers that up to $75 \%$ of horses affected by this disease eventually develop severe or chronic lameness and debilitation. ${ }^{1}$ As emphasized by Orsini and colleagues $^{2}$ inflammation emerges as the common pathological denominator in all cases of laminitis and thus also disease-related pain. It is intimately associated with the cascade of events that may eventually lead to the complete failure of the lamellar dermal-epidermal bond. Inflammation and vascular dysfunction are evident in the early developmental phase of laminitis, when pain or other clinical symptoms are still absent. ${ }^{3-5}$ During this prodromal phase leucocyte extravasation and development of platelet microthrombi are accompanied by up-regulated gene expression for key inflammatory cytokines (e.g. interleukin [IL]-1 $\beta$, IL-6), cyclooxygenase (COX)-2, and matrix metalloproteinases (MMPs) in the digital laminae. ${ }^{5-9}$ Locally released and activated MMPs mediate degradation of the collagen components of the basement membrane (BM) that is interposed between the secondary dermal (SDL) and epidermal lamellae (SEL) and cause a separation of the SEL from the BM. ${ }^{4,10-14}$

Sensory innervation of the foot consists of thick myelinated A-fibers (largely $A_{\beta}$ ) transmitting low-threshold mechanical information and small thin myelinated ( $A_{\delta}$-fibers) and un-myelinated afferents (C-fibers) which express a variety of peptides and transmit high-threshold nociceptive information. ${ }^{15-19}$ The $\mathrm{A}_{\beta}$ fibers innervate lamellated corpuscles (comparable with Pacinian corpuscles) clustered below the digital cushion in the heel segment of the hoof that function as proprioceptors and provide a secure gait. ${ }^{17,19}$ Both nociceptive $A_{\delta^{-}}$and C-fibers that stain 
immunohistochemically positive for calcitonin gene-related peptide (CGRP) and substance P (SP) and are widely distributed throughout the base of the dermal layer (especially dermal papillae in the solear and bulbar segment and dermal lamellae in the parietal segment) and run parallel to blood vessels without innervating them. ${ }^{17-19}$ In addition, slow-conducting un-myelinated nerve fibers of the autonomic (exclusively sympathetic) nervous system accompany the dense network of blood vessels and arteriovenous anastomoses within the hoof capsule. ${ }^{19,20}$ As in visceral organs, these sympathetic nerves not only carry efferent fibers that regulate vasomotor tone, sweat glands and pilo erector muscles in the skin but also afferent viscerosensory fibers that signal information about vascular lumen, wall stress, and noxious stimulation or hypoxic/ischemic tissue conditions to the central nervous system (CNS). ${ }^{19}$ Hence, they may contribute to sympathetically maintained nociceptive stimulation typically unresponsive to conventional analgesics.

The inflammatory and disadhesion processes that occur during the developmental phase of laminitis do not seem to influence activity in sensory nerve fibers of the hoof. Histological data suggest that the disruption of the dermo-epidermal laminar bond is initially confined to the noninnervated basement membrane and epidermal lamellae (grade 1 histological laminitis). ${ }^{4,21}$ Since sensory nerve terminals are located primarily at the base of the dermal lamellae, at this stage of the disease they are likely too distant to the site of MMP action to be affected and SEL cell injury and local inflammation are not severe enough to cause activation through neurochemical signaling. Lacking pain or discomfort the developmental phase of laminitis often goes unnoted and therefore treatment is not initiated even though aggressive medication with non-steroidal antiinflammatory drugs (NSAIDs) has been claimed to be indicated. ${ }^{7,8}$

Unless resolving on their own histological changes at the dermal-epidermal interface progress further causing within 24-72 hours the BM to retract so much from SEL that SDL connective tissue and SDL capillaries are injured by tension and shear forces (grade 2 histological laminitis), ${ }^{4}$ likely provoking activation of perivascular sensory nerve terminals near the base of the dermal lamellae. At this point the developmental phase transits into the acute phase of laminitis that is hallmarked by classical signs of inflammation such as bounding digital pulses and increased hoof temperature. ${ }^{3-5}$ Nociception is most often recognized by lameness or the characteristic stance of the animal and rapidly increasing sensitivity to hoof testers. ${ }^{3,5}$ Even though evidence for a marked increase in COX-2 enzyme activity could not be found in the acute phase of experimentally induced laminitis, ${ }^{8}$ concentrations of other vasoactive degradation products of arachidonic acid (e.g. isoprostanes) are elevated during the acute phase of experimentally induced laminitis. ${ }^{9}$ In addition, extensive necrosis 
of the SEL and edema with separation of the dermal-epidermal junction has been noted in the acute phase of experimentally induced laminitis. ${ }^{21}$ Thus, it is most likely that sensitization (peripheral hyperalgesia) develops secondary to the action of a variety of locally released inflammatory products. ${ }^{15,16,22}$ As described in other situations of tissue damage, changes in the local environment (e.g. tissue $\mathrm{pH}$ and local electrolyte $\left(\mathrm{K}^{+}\right)$concentrations, accumulation of membrane degradation products, cytokines, chemokines, and growth factors from invading inflammatory cells) and upregulated enzyme systems may collectively activate both expressed and silent nociceptors and sensitize them to noxious and even non-noxious stimuli. ${ }^{22}$ Furthermore, activated sensory nerve fibers in the dermal papillary layer release neuropeptides (e.g. CGRP) which target receptors on blood vessels and provoke neurogenic inflammation by causing vasodilation, plasma extravasation, and leucocyte attraction. ${ }^{18,19}$ Even during the acute phase of laminitis, persistent afferent nociceptive signaling will initiate neural processes (addressed in detail below) that eventually create a state of central potentiation of nociceptive input to the brain (central hyperalgesia) ${ }^{22}$ mediated in part by spinal release of excitatory amino acids, tachykinins, prostanoids and cytokines. ${ }^{16}$ Some of these products reflect the activation of not only neurons, but also non-neuronal cells (astrocytes and microglia) which contribute to the release of products (e.g. prostaglandins) that in turn increase excitability of dorsal horn neurons. ${ }^{16,22}$ Both peripheral and early central hyperalgesia may explain the rapidly worsening pain horses and ponies experience in the acute phase of laminitis.

Animals may pass through the acute phase of mild and moderate laminitis without having developed any gross structural changes to the dermal-epidermal lamellar apparatus, allowing for complete recovery from all symptoms including pain. If not, they enter within 2-3 days the chronic phase of laminitis that begins with separation of the distal phalanx from the hoof wall and subsequent mechanical collapse of the foot. ${ }^{3-5}$ It can be subdivided into three subphases, i.e. early chronic, chronic stable, and active chronic laminitis. ${ }^{23}$ It is during the early chronic or active chronic phase of the disease process that relenting pain may develop which often is very difficult to control with traditional antiinflammatory and analgesic drug treatment. ${ }^{24}$ However, some animals may pass the early chronic phase rather rapidly without showing severe symptoms and enter the stage of chronic stable laminitis. At this stage they may not display any significant lameness allowing even athletic performance despite unequivocal radiographic evidence of displacement of the distal phalanx. ${ }^{21}$

The pain animals with chronic laminitis suffer is multifactorial and greatly variable. The pathophysiological sequela occurring after structural failure of the lamellar suspensory apparatus in 
one animal may or may not occur to the same extent in another and the type and scope of tissue repair and remodeling varies among individual horses. ${ }^{21} \mathrm{~A}$ major component determining the degree of nociception is the extent of mechanical/structural failure of the foot's submural tissues, with global distal displacement of the digital phalanx ('sinking') probably representing the worst scenario. Tearing of the dermal-epidermal lamellar bond with rotation or sinking of the coffin bone results in widespread injury to $\mathrm{C}$ - and $\mathrm{A}_{\delta}$-fibers in the dermal layers. Damaged sensory neurons produce spontaneous impulse discharges that lead to sustained levels of excitability. ${ }^{22}$ These ectopic discharges begin to "cross talk" with adjacent uninjured nerve fibers, resulting in amplification of the response to noxious stimulation as part of the peripheral hyperalgesia that develops in the injured tissue. Distal phalanx displacement also leads to increased submural pressure from the edema that accompanies inflammation and/or hemorrhage. ${ }^{21}$ :Loss of digital stability with significant shifts in the distribution of strain and stress forces within the hoof capsule contribute to both mechano- $\left(A_{\beta}\right)$ and nociceptor $\left(A_{\delta}, C\right)$ activities, as does elevated pressure on the coffin bone due to greater and longer lasting contact between the internal surface of the sole and the distal phalanx during locomotion. ${ }^{21}$ Elevated eicosanoid $\left(\mathrm{PgE}_{2}, \mathrm{LTB}_{4}\right)$ concentrations have not been detected in digital venous blood of painful horses during chronic laminitis. ${ }^{25}$ Nevertheless, it appears that inflammatory mediators released throughout all phases of laminitis play a dominant role in the pain perception during early and active chronic laminitis. ${ }^{2,15,16,19}$ Furthermore, digital ischemia resulting from tearing of SDL arterioles, vasoconstriction (primarily venoconstriction) in response to inflammatory mediators, arteriovenous blood shunting, thrombosis, and compression of the solar vascular bed after digital collapse may contribute important causative factors for pain. ${ }^{3-}$ 5,22,24,26 Also dilation of hoof vessels in response to release of neuropeptides (e.g. CGRP) from activated sensory nerve terminals leads to a rapid increase in pressure within the hoof capsule (similar to the situation within the skull after vasodilation), thereby exacerbating foot pain. ${ }^{19,20}$

The factors mentioned above only partially explain why many animals with chronic laminitis experience persistent and often times worsening pain that is refractory to therapy, while other animals are spared or recover. While not studied in detail in horses with laminitis, data obtained with laboratory animal models and clinical observations in human patients with severe tissue injury indicate that lesions to peripheral somatosensory neurons can trigger a complex series of events that eventually alter peripheral nerve impulse signaling and central nervous sensory input processing. These processes result in a pain state commonly referred to as neuropathic pain, i.e. pain that has its origin in a lesion or dysfunction of the sensory transmission pathways in the peripheral or central 
nervous system itself, and thus is considered a pathological condition in and of itself..$^{15,16,23,27-30}$ The changes may include but are not limited to: i) large increases in spontaneous (ectopic) activity in injured afferent nerve fibers and dorsal root ganglia (DRG) cell bodies; ii) ectopic activity in nociceptors resulting from local increase in sodium channel expression and enhanced sensitivity to excitatory products released from local inflammatory cells; iii) facilitation of synaptic neurotransmission in the dorsal horn through increased release of or response to excitatory neurotransmitters (e.g. NMDA, glutamate) and/or increased ion channel conductance; iv) loss of dorsal horn inhibition otherwise mediated by spinal GABA- or glycinergic interneurons; v) reduced sensitivity of primary sensory afferents and dorsal horn neurons towards the effects of $\mu$-opioid agonists; vi) sprouting of central sympathetic nerve fiber terminals into layers of the dorsal horn where they can make abnormal contacts with ascending sensory neurons causing "sympathetically maintained pain"; vii) loss of synaptic connectivity and formation of new synaptic contacts between low-threshold $A_{\beta}$ fibers and ascending sensory neurons that normally receive input only from nociceptive $A_{\delta}$ and $C$ fibers, causing allodynia (table 2); viii) activation of astrocytes and microglia leading to an increased spinal expression of pro-excitatory products including prostanoids; and ix) neuroimmune interactions including actions of MMPs 9 and 2 capable of inducing neuropathic pain through microglial and astrocyte activation. ${ }^{15,27-31}$ Ectopic neural firing activity occurs within 12 to $48 \mathrm{hrs}$ after nerve injury, while sensitization and gene expression changes in spinal and maybe supraspinal neural networks begin later. Neural lesions alone may not be sufficient to generate neuropathic pain and other predisposing factors are of importance. ${ }^{29}$ Nevertheless, Jones and collaborators $^{24}$ found in horses suffering from recurrent and treatment refractory laminitis, neuromorphological changes and altered gene expression that are strikingly similar to those changes observed in animal models of peripheral nerve injury or in humans with neuropathic pain (e.g., from arthritis, osteosarcoma, or diabetes). ${ }^{16}$ The nerve fiber composition of digital nerves harvested from affected animals was abnormal with significantly lower numbers of un-myelinated (43.2\%) and myelinated fibers $(34.6 \%)$ compared to nerves collected from normal horses. ${ }^{24}$ Furthermore, upregulated expression of activating transcription factor-3 (ATF3), a classical marker of peripheral nerve injury, was found in DRG cells of both large and small afferents. Also neuropeptide Y (NPY) expression was increased in DRG cells of large myelinated fibers innervating the laminitic hoof. The abundant presence of MMPs 2 and 9 from the developmental phase onwards may yet be another factor contributing to the development of neuropathic neural injury. ${ }^{4,31}$ Thus, it appears that mechanisms of peripheral and central sensitization and neuropathic remodeling described above can 
play a central role in the development of the unrelenting pain experienced by so many horses during chronic laminitis. ${ }^{16,29,30}$ In this pain state mildly noxious or subthreshold stimuli (transmitted by small $\mathrm{A}_{\delta^{-}}$and $\mathrm{C}$-afferents) produce an exaggerated pain response due to amplified pre- and postsynaptic neuronal sensitivity and activity. ${ }^{24}$ Normally innocuous mechanical stimuli such as those activating the lamellated corpuscles and low threshold $\mathrm{A}_{\beta}$ fibers in the heel area when the foot touches the ground during locomotion may then be perceived as painful (tactile or mechanical allodynia). ${ }^{27,30}$ This may explain the frequent limb shifting and high sensitivity to the hoof tester.

\section{GRADING PAIN IN LAMINITIS}

Various scoring systems employing either behavioral characteristics only or both behavioral and physiological parameters have been developed to monitor pain in horses. ${ }^{32}$ Obel $^{33}$ was among the first to describe a grading system for lameness in horses affected by laminitis. Both the Obel Grading System and the later developed graded lameness scale (0-5) of the American Association of Equine Practitioners ${ }^{34}$ are subject to high inter-observer variability, do not fully account for the complexity of equine pain behaviors, and are somewhat limited when assessing clinically relevant changes in nociception and responses to therapy. Dutton and colleagues ${ }^{35}$ recently applied a modified composite multifactorial pain scoring system that includes components of the Obel Grading System and the Glasgow composite pain scale in a horse suffering from severe persistent foot pain (Table 1). As the authors emphasize multiple observers produced consistently similar scores when assessing the pain state in the horse and changes in scores tightly followed responses to analgesic treatment and progress in the disease process. To objectively assess and quantify pain (lameness) in acute and chronic laminitis, force plate systems have been used for measuring ground reaction forces and other force parameters and to identify changes in limb-load distribution pattern that reflect changes in the disease process and responses to treatment. ${ }^{36,37}$

\section{PAIN THERAPY IN LAMINITIS: MODIFYING THE APPROACH}

Until very recently pain therapy in acute and chronic laminitis has largely been based on the proposed etiopathogenetic mechanisms underlying the disease (i.e. vascular or thromboembolic ischemia; inflammatory; metabolic; enzymatic and biomechanical mechanisms) and consisted predominantly of antiinflammatory drug administration. ${ }^{38-48}$ In the acute phase this therapy was often combined with other medications (e.g., acepromazine, pentoxifylline, isoxuprine, heparin, acetyl salicylic acid, nitroglycerin, 
dimethyl sulfoxide) addressing suspected ischemia and reperfusion injury (oxidative damage) in the dermalepidermal lamellae, yet with conflicting results. ${ }^{39-43,45,46-48}$ This traditional approach failed to control the multifactorial pain in horses with chronic laminitis, because pain has been considered only a symptom of laminitis rather than a pathological entity in itself. It is the abnormal neural signal processing due to damage to tissues (inflammatory pain) and nervous structures (neuropathic pain), and/or abnormal function of the nervous system as a whole (functional pain) that over the course of the disease process causes a state of nociception that is commonly referred to as pathological or maladaptive pain. ${ }^{30,49}$ Conventional non-steroidal anti-inflammatory (NSAID) and other medications may not or only partially target the neuropathophysiological mechanisms described in detail above. ${ }^{15,16,29,32}$ Therefore, shifting the focus towards a more holistic strategy aimed at preventing maladaptive pain or at least reducing the risk of its occurrence appears to be more indicated. ${ }^{28,32,35}$ This concept follows the notion that i) events leading to acute pain, peripheral and central hyperalgesia, neuropathic pain, with or without allodynia occur simultaneously and are interrelated; ii) drugs may exhibit a specific activity against only certain components of the pain syndrome; iii) early integration of drugs with anti-hyperalgesic or anti-neuropathic pain activity into the treatment plan promises to reduce the risk of maladaptive pain development; and iv) loco-regional analgesia techniques help suppressing the occurrence of hyperalgesia and neuropathic pain. ${ }^{32}$ Accordingly, effective pain management in horses with laminitis favors a multi-modal approach that involves, from the beginning, a combination of drugs with different pharmacological mechanisms of action and different target sites within the somatosensory neural conduit (Figure 1). This concept may also include podiatric care, electrotherapy, tenotomy or botulinum toxin-induced relaxation of the deep digital flexor tendon, physical therapy, and other complementary modalities of treatment, most of them aimed at altering biomechanical forces on the affected digit with decreased foot pain perception and improved recovery. ${ }^{32,35,41,42,44,45,50-54}$

To have sustainable success pain therapy in the horse with chronic laminitis has to accomplish multiple goals: i) reduction of nociceptive signal generation in sensory nerve terminals (NSAIDs, podiatric care); ii) suppression of peripheral hyperalgesia (NSAIDs, local anesthesia and analgesia); iii) Inhibition/prevention of afferent nociceptive signal transmission to the central nervous system (loco-regional analgesia); iv) inhibition of spinal nociceptive signal transmission and central hyperalgesia development ([epidural/spinal: local anesthetics, opioids, $\alpha_{2}$ agonists], [systemic: opioids, $\alpha_{2}$ agonists, ketamine, NSAIDs, gabapentin, pregabalin]) and v) prevention and/or inhibition of neuropathic pain (systemic lidocaine, opioids, NSAIDS, gabapentin, pregabalin). Multi-modal pain therapy is mechanism driven and should be evidence based. It 
represents a concept that is very open and allows new drugs and techniques to be included as they become available.

As mentioned before, neither pathological mechanisms leading to nor treatment of sensory hyperalgesia and neuropathic pain have yet been studied in detail in horses. At this stage, the equine veterinarian must rely primarily on experimental animal data and experiences in human medical practice when developing an analgesic regimen for the horse with chronic foot pain. There are a number of lessons to be learnt from experiences with neuropathic pain therapy in the human patient: i) symptoms described by patients are many, including those listed in Table 2, and therefore the diagnosis of neuropathic pain is often challenging and diagnostic criteria are still evolving; ii) rarely, if ever, can one single pathophysiological mechanism be claimed responsible for generating and maintaining the symptoms of neuropathic pain; iii) individual variation in the response to anti-neuropathic pain medications is substantial and unpredictable, thus favoring a stepwise process intended to identify the medication (or medication combination) that provides the greatest pain relief and fewest side effects while discontinuing drugs lacking an analgesic effect; iv) currently first line medications for neuropathic pain cannot be ranked by degree of efficacy; v) no more than $40-60 \%$ of patients with neuropathic pain will respond favorably to pharmacological treatments. ${ }^{55-59}$

Whatever pharmacological or other approach and technique is chosen in an individual multi-modal protocol, the ultimate objective is to achieve optimum pain control during each phase of laminitis, while at the same time minimizing the risk of negatively affecting the disease process itself or causing side effects of drug therapy. ${ }^{32}$ 


\section{Conventional systemic analgesics}

Three different pharmacological classes of drugs are commonly administered systemically to treat pain in horses affected with laminitis: NSAIDs, opioids and lidocaine. As described in more detail below, these drugs have also the potential to ameliorate nociceptive processes involved in the development of hyperalgesia and neuropathic pain.

\section{NSAIDs}

The backbone of any pharmacological pain therapy in laminitis has been and continues to be treatment with NSAIDs (Table 3). Evidence of increased cyclooxygenase (primarily COX-2) expression, leucocyte migration, and cytokine production in the developmental and acute phases of laminitis as outlined above indicated a role for these agents, optimally prior to the onset of lameness. However, there is increasing evidence to suggest that commonly administered NSAIDs such as phenylbutazone, flunixine meglumine, ketoprofen, and naproxen do not mediate their effects through antiinflammatory action (i.e. prostanoid synthesis inhibition) in the affected dermoepidermal hoof tissues but instead produce analgesia primarily by inhibition of central sensory neurons through COX-dependent and other independent mechanisms. ${ }^{40,43,46,60}$ First, administration of NSAIDs during the developmental stage, when COX-2 expression is upregulated, does not seem to prevent acute laminitis or alter the course of the disease arguing against a dominant antiinflammatory action. ${ }^{61}$ Second, increased prostaglandin activity has not been detected in the acute and chronic phases of laminitis despite evidence for ongoing inflammation, ${ }^{8,9,21,25}$ supporting the notion that if NSAIDS exhibit antiinflammatory activity at high doses this effect may not be related to inhibition of prostanoid synthesis. ${ }^{43,46}$ Third, unlike in peripheral tissues, where COX-1 is constitutively present for tissue homeostasis and COX-2 is inducible by inflammation, ${ }^{62}$ both COX isoforms are constitutively present in the CNS but with functionally different roles. ${ }^{63,64}$

While NSAID administration in higher doses with antiinflammatory activity may be desirable in the very early (developmental) stage of laminitis, in the acute phase persistent and very effective pain relief from NSAIDs must be balanced against the risks of exacerbated structural damage due to excessive movement and limb loading of the horse, ${ }^{40,47}$ and thus the dose should be titrated based on the comfort level of the animal. In horses with chronic laminitis, effective analgesia frequently calls for high doses of NSAIDs and an effect may still not be seen for up to 3 days after initiation of treatment. ${ }^{40}$ This must be considered when assessing the clinical response to NSAIDs. 
The previously held belief that more COX-2 preferential (meloxicam, Metacam ${ }^{\circledR}$; etodolac, Etogesic $^{\circledR}$ ) or even COX-2 selective NSAIDS (firocoxib, Equioxx ${ }^{\circledR}$ ) are therapeutically superior has been challenged recently. ${ }^{65-67} \mathrm{New}$ laboratory data indicate that suppression of inflammationevoked central nociceptive activity and hyperalgesia by NSAIDs may be related to the selectivity for COX isoforms since COX-2 seems to be only involved in the initiation but not necessarily the maintenance of nociceptive spinal neuron activation, which may largely depend on COX-1. ${ }^{64}$ In contrast, in the absence of peripheral inflammation spinally initiated hyperalgesia has been shown to be mediated exclusively by constitutive COX-2 likely localized within the spinal cord dorsal horn, which argues for a prominent indication of selective COX-2 inhibitors as antihyperalgesic agents under circumstances of non-inflammation dependent central nociceptive sensitization. ${ }^{63}$ Under the premise of inflammation being the common pathological denominator ${ }^{2}$ and hence the trigger for increased spinal sensory nerve excitability in all forms of laminitis, these laboratory findings suggest the use of non-selective NSAIDs as more effective candidates for analgesic therapy in laminitis. This idea is supported by two observations: i) among clinicians the nonselective COX inhibitor phenylbutazone is considered the most potent and most consistent pain relieving NSAID in laminitis; ${ }^{47,60,67}$ and ii) only ketoprofen $(3.63 \mathrm{mg} / \mathrm{kg}$ ), a slightly COX-1 preferential NSAID ${ }^{68}$ may reduce foot pain to a greater extent than phenylbutazone $(2.2 \mathrm{mg} / \mathrm{kg}){ }^{69}$ Interestingly, the stereoisomers of ketoprofen are known to exert antinociceptive actions also through mechanisms other than COX inhibition. The R(-)-enantiomer of ketoprofen suppresses tactile allodynia via a yet to be defined mechanism of action and the $\mathrm{S}(+)$-enantiomer produces analgesia through mechanisms involving serotoninergic pathways both at the spinal and supraspinal level. ${ }^{70,71}$ In addition, ketoprofen has been demonstrated to exert antihyperalgesic activity in dairy cows suffering from unilateral hindlimb lameness. ${ }^{72}$

A risk of toxicity must be anticipated in animals receiving protracted courses of NSAID treatment. $^{65,67,73}$ Of interest, NSAIDs have been shown in-vitro to slightly potentiate MMP activation, ${ }^{47}$ which cautions against an indiscriminate use in the early stages of laminitis. Currently most widely used NSAIDs are non-selective and may cause multiple adverse effects (i.e. right dorsal colitis, gastric ulceration, and renal tubular necrosis) through inhibition of COX-1. This applies particularly to phenylbutazone which has a longer elimination half life and thus accumulates more extensively in tissues than other non-selective NSAIDs. ${ }^{44,73}$ Therefore, their use may need to be restricted in horses with compromised gastro-intestinal or renal functions or in dehydrated animals, and in ponies that are more susceptible to toxic effects of NSAIDs. ${ }^{43,46,74}$ In those cases 
COX-2 preferential/selective agents and ketoprofen, that have a more favorable side effect profile compared to phenylbutazone and flunixine meglumine, may be better choices to treat persistent pain in laminitis. ${ }^{75,76}$

\section{OPIOIDS}

Opioids (Table 4) are generally indicated in moderate to severe pain, however, their analgesic efficacy in horses compared to other species is less well defined, especially when used in clinically common doses. ${ }^{60,77,78}$ At higher doses known to produce significant analgesia or antinociception (e.g., butorphanol, methadone, or morphine $\geq 0.1 \mathrm{mg} / \mathrm{kg}$ ) opioids commonly provoke central excitatory responses, requiring combination with sedatives such as acepromazine or $\alpha_{2}$ agonists (Table 4). ${ }^{60,77,78}$ In, addition, they decrease gastrointestinal motility and cause colon impaction, thus limiting their long-term use in animals with chronic laminitis. Combining lower doses of $\mu$-opioids with low doses of $\alpha_{2}$ agonists (preferably in the form of a constant rate infusion [CRI]) may help achieve a desired level of analgesia by making use of the well known analgesic synergism between the two drug classes, while avoiding the profound CNS stimulatory effects of the opioids and hemodynamic effects of the $\alpha_{2}$ agonists (Table 4). ${ }^{78}$ However, impaired intestinal motility, caused by both opioids and $\alpha_{2}$ agonists, remains a concern with long-term treatment. Whether opioids elicit less CNS stimulatory effects and are therapeutically more effective in horses experiencing severe pain is controversial because scientific evidence is lacking. ${ }^{79}$ Controlled trials in human patients revealed efficacy of opioids against peripheral neuropathic pain and some components of central neuropathic pain ${ }^{56,57}$ However, there is also laboratory animal and human clinical evidence that long-term use of $\mu$ opioid agonists such as morphine can trigger the development of a state of opioid induced hyperalgesia $(\mathrm{OIH})$ whereby a subject receiving opioids for the treatment of pain may actually become more sensitive to pain. ${ }^{80-82}$ This potentially profound adverse effect should be considered when prescribing long-term opioid therapy in horses with chronic laminitis, even if the mechanisms leading to $\mathrm{OIH}$ and its clinical relevance are still being debated, and the phenomenon is not described in horses. ${ }^{83}$

Butorphanol (Torbugesic ${ }^{\circ}$ ), a $\kappa$ opioid receptor agonist and $\mu$-receptor antagonist, is probably the most widely used opioid in horses. The drug's short half-life limits its use as analgesic in laminitis, calling for a CRI to achieve persistent analgesia. ${ }^{84,85}$ Transdermal administration of fentanyl (Duragesic ${ }^{\circ}$ ), a potent but very short-acting synthetic $\mu$-opioid receptor agonist, has been found to not consistently alleviate musculoskeletal pain. ${ }^{86,87}$ If fentanyl patches were to be used as part of the multimodal pain management one should probably apply at least as many patches as necessary to achieve plasma fentanyl levels 
generally considered to be analgesic in other species (i.e. $\geq 1 \mathrm{ng} / \mathrm{mL}$ ). ${ }^{88}$ Buprenorphine (Buprenex ${ }^{\circ}$ ) is a $\mu$ opioid agonist and $\kappa$-opioid antagonist, which has been claimed to have a ceiling effect. ${ }^{77}$ When applied as a sole analgesic agent in horses, measurable antinociception has been reported to occur at doses of 10 $\mu \mathrm{g} / \mathrm{kg}$ or higher but significant excitement and hemodynamic stimulation were noted as well. ${ }^{89}$ Walker $^{90}$ reported recently about experience with a 5-day administration of buprenorphine in a filly with severe head and neck trauma choosing the sublingual/buccal mucosal route. The drug provided clinically effective analgesia, when given twice daily, without provoking signs of excitement.

\section{SYSTEMIC LIDOCAINE}

The clinical use of systemic lidocaine for pain treatment in humans was first reported almost five decades ago, ${ }^{91}$ and during the past 10 years has gained much popularity also in equine practice. ${ }^{32,78,92-95}$ The drug must be administered as CRI due to its short half-life. ${ }^{96}$ A loading dose of 1.3 to $1.5 \mathrm{mg} / \mathrm{kg}$ administered IV over 15 minutes (min) followed by a CRI of 50-100 $\mu \mathrm{g} \bullet \mathrm{kg}^{-1} \cdot \mathrm{min}^{-1}$ is most commonly used. ${ }^{78,79}$ Data regarding the immediate analgesic effect of lidocaine on spontaneous (not evoked) pain in animals or patients are somewhat inconsistent when infused at clinically common doses, ${ }^{78,91,97,98}$ and higher doses carry the risk of cardio- and neurotoxicity. ${ }^{86,94}$ Since plasma concentrations achieved during long-term infusion vary widely among horses and may accumulate over time, ${ }^{78,95,96,100,101}$ monitoring of plasma levels (via a lidocaine ELISA kit; Neogen Corporation, Lansing, MI 48912, USA) is recommended, not only to avoid toxicity but also to ensure that analgesically effective concentrations (approx. $\geq 1 \mu \mathrm{g} / \mathrm{mL})^{91,95}$ are being achieved.

Information available to date indicates that the analgesic action of IV lidocaine is far more complex than previously thought. Besides its well studied local anesthetic actions (i.e. $\mathrm{Na}^{+}$channel blockade) in the peripheral and central nervous system, it also exerts multiple other mechanisms of action that target the nociceptive system (spinal and supraspinal). ${ }^{102-104}$ Both laboratory animal and controlled clinical trials in humans have found IV lidocaine to suppress development of peripheral hyperalgesia as well as central nociceptive sensitization and allodynia. ${ }^{103-107}$ Its efficacy as an analgesic and anti-neuropathic agent has recently been demonstrated in adult patients suffering from chronic pain with tactile hyperalgesia and/or mechanical allodynia for more than 3 months as a result of a peripheral nerve injury. ${ }^{98}$ In this trial ${ }^{98}$ IV lidocaine failed to produce an alleviation of the spontaneous pain the patients were suffering from the nerve injury, similar to findings in a previous 
study from the same investigator group. ${ }^{97}$ However it is also reported elsewhere that systemic lidocaine inhibits spontaneous pain. ${ }^{91,107}$

In addition to its analgesic and antihyperalgesic/anti-neuropathic properties described above lidocaine also has inflammation modifying effects and has been shown to protect tissues against ischemic and reperfusion injuries in various species including the horse, ${ }^{108-112}$ which may all have a direct or indirect impact on the laminitis disease process and thus related nociceptive mechanisms and pain perception. 


\section{Non-conventional systemic analgesics with anti-hyperalgesic and anti-neuropathic pain activity}

Three evidence-based consensus guidelines for the pharmacologic treatment of neuropathic pain have been published recently in the human medical literature. ${ }^{57-59}$ These guidelines all recommend tricyclic antidepressants (not tested in the equine species) and calcium channel $\alpha_{2} \delta$ ligands (gabapentin, pregabalin) as first-line treatments for patients with neuropathic pain. They suggest reserving opioid analgesics and N-methyl-D-aspartate (NMDA) receptor antagonists as second- or third-line options in most cases, despite evidence of efficacy in certain forms of hyperalgesia and neuropathic pain. ${ }^{58}$ In two of the guidelines topical lidocaine was recommended as a first-line treatment for patients with localized peripheral neuropathic pain. ${ }^{57-59}$

\section{CALCIUM CHANNEL $\alpha_{2} \delta$-LIGANDS (GABAPENTIN, PREGABALIN)}

The anticonvulsant drugs gabapentin and pregabalin both bind with high affinity to the $\alpha_{2} \delta$ 1 subunit of voltage-gated calcium channels in the spinal cord and brain. ${ }^{114}$ As a result neuronal calcium currents are inhibited, ultimately causing a change in the release of neurotransmitters within the CNS such as glutamate, GABA, norepinephrine, and SP; these actions account for much of the analgesic activity of these compounds. ${ }^{115,116}$ The expression of the $\alpha_{2} \delta-1$ subunit has been shown to increase in chronic pain states, as well as in both afferent sensory neurons and in the spinal cord dorsal horn in experimental neuropathic pain models. ${ }^{117,118}$ This correlates well with the observation that gabapentin exerts analgesic properties primarily in sensitized or hyperalgesic states. ${ }^{119,120,121}$ More recently gabapentin and pregabalin have been used clinically in humans to treat a variety of neuropathic pain states and early post-surgical pain, often but not always with success. ${ }^{55-59,122}$ These drugs appear especially effective in patients with paroxysmal pain (lancinating/shooting pain), brush-induced allodynia and cold-induced allodynia/hyperalgesia, in whom it significantly lowers pain scores. ${ }^{123}$ Laboratory animal data suggest the $\alpha_{2} \delta$-ligands also have activity against opioid-induced hyperalgesia. ${ }^{124}$

Documented therapeutic use in horses refers only to oral (PO) administration of gabapentin $\left(\right.$ Neurontin $\left.^{\circledR}\right)$ in two animals which were thought to exhibit signs of neuropathic pain, one in conjunction with acute femoral nerve injury post-surgery and one with a history of white line disease and chronic laminitis. ${ }^{35,125}$ Lacking information on pharmacokinetic properties of the drug in the equine at that time, gabapentin doses were extrapolated from use in other species $(2.5 \mathrm{mg} / \mathrm{kg}$ 
at intervals of 8,12 or $24 \mathrm{hrs} ;{ }^{124} 2.0-3.3 \mathrm{mg} / \mathrm{kg}$ at intervals of 8 or $12 \mathrm{hrs}^{35}$ ). In the meantime two studies have been conducted in horses investigating the drug's pharmacokinetic properties as well as behavioral and cardiovascular parameters after IV and PO administration. ${ }^{126,127}$ After IV (over 30 $\min )$ and PO administration of gabapentin $(20 \mathrm{mg} / \mathrm{kg})$, the median elimination half-lives were 8.5 and $7.7 \mathrm{hrs}$, respectively which correspond well with data in other species. ${ }^{126}$ After IV administration plasma gabapentin concentrations remained above the $3-4 \mu \mathrm{g} / \mathrm{mL}$ range for approximately $15 \mathrm{hrs}$, similar to the dose associated with significant analgesic effects in adult human volunteers. ${ }^{128}$ In the horse, oral bioavailability of gabapentin is relatively poor $(\sim 16 \%)$ and therefore plasma gabapentin concentrations decreased much more rapidly than after IV drug administration (i.e. within 2-3 hrs) below the analgesic threshold. Neither route of gabapentin administration was associated with effects on heart rate, rhythm or blood pressure, nor pronounced central nervous effects, which concurs in other species. ${ }^{127}$ Further research is required to establish a dosage that will provide effective analgesia in horses with chronic laminitis and to determine if combinations with other agents create an enhanced effect.

\section{KETAMINE}

Peripheral sensory nerve stimulation leads to activation of the ligand-gated ion channel complex known as N-methyl-D-aspartate (NMDA) receptors on the postsynaptic membrane in the dorsal horn of the spinal cord. Release of NMDA, a modulating neurotransmitter, is coupled with subsequent release of the excitatory neurotransmitter glutamate. ${ }^{22}$ The resultant extended depolarization of sensory neurons produces much larger than usual postsynaptic potentials, known as synaptic potentiation, a key component of central hyperalgesia as well as synaptic plasticity leading to chronic pain. ${ }^{22,129,130}$

Ketamine is an NMDA receptor antagonist. ${ }^{131,132}$ At subanesthetic doses $(100-150 \mu \mathrm{g} / \mathrm{kg}$ as initial bolus followed by a CRI of $60-120 \mu \mathrm{g} \mathrm{kg}^{-1} \bullet \mathrm{hr}^{-1}$ ) it blocks NMDA receptors, thereby modulating central sensitization induced both by tissue damage. ${ }^{133-137}$ Ketamine exhibits synergism with classical analgesics such as opioids, NSAIDs, local anesthetics and $\alpha_{2}$ agonists; therefore it reduces opioid analgesic consumption and increases analgesic quality. ${ }^{135-137}$ Ketamine is used primarily as an antihyperalgesic and anti-allodynic compound in human patients at risk of developing maladaptive pain after major tissue damage and not primarily as an analgesic agent per se. $^{138}$ 
Clinical effects of subanesthetic ketamine infusion (400 and $800 \mu \mathrm{g} \bullet \mathrm{kg}^{-1} \bullet \mathrm{hr}^{-1}$ ) have been studied in awake horses. ${ }^{139}$ During or following the $12 \mathrm{hr}$ infusion no analgesic effects could be demonstrated and no signs of excitement or significant changes in measured physiological variables occurred. A CRI of $400-1500 \mu \mathrm{g} \bullet \mathrm{kg}^{-1} \bullet \mathrm{hr}^{-1}$ has been used safely in conscious horses. ${ }^{140}$ However, with both infusion regimens the measured plasma ketamine concentrations were about 10 times below concentrations $(2-4 \mu \mathrm{g} / \mathrm{mL})$ associated with measurable acute antinociceptive effects. ${ }^{141}$

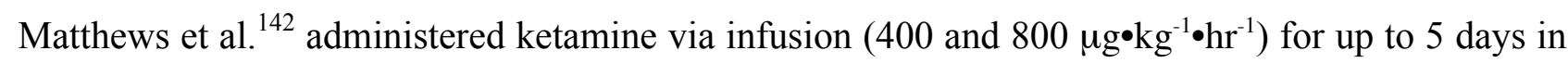
eight horses with osteomyelitis, septic joint disease, burns, or colic in a search for possible analgesic effects. Responses to ketamine varied substantially with some showing any or only slight improvements of pain symptoms, while others appeared to be markedly more comfortable within 6 to $12 \mathrm{hrs}$ of the start of drug infusion. Thus, in horses as in humans, low dose ketamine infusion should be considered an adjunctive therapy for treating central hyperalgesia.

\section{Loco-regional anesthesia and analgesia}

The neuropathophysiological processes leading to the development of central hyperalgesia, neuropathic pain and allodynia are primarily triggered by increased spontaneous firing activity in ascending sensory nerve fibers during the first 4-5 days following peripheral nerve injuries. ${ }^{143-145}$ Experimental evidence and clinical experiences in human medicine indicate that central hyperalgesia can be obliterated by no other treatment modality as effectively as by loco-regional anesthesia and analgesia aimed at interrupting or diminishing impulse trafficking from the site of tissue injury to the CNS and within the dorsal horn of the spinal cord. ${ }^{56,59,78,143-147}$ Those techniques may include wound infiltration or joint injections with local anesthetics, topical local anesthetic application using lidocaine patches, repetitive or even better continuous peripheral nerve blocks, and epidural or intrathecal anesthesia and analgesia.

Continuous peripheral nerve blockade (CPNB) is a treatment modality that has been long introduced in human medicine and is currently widely applied in orthopedic and trauma surgery. The technique entails continuous or intermittent low-dose administration of local anesthetics via catheters placed along peripheral nerves, thus providing persistent pain control while reducing the need of systemic medications. ${ }^{148}$ A technique for percutaneous placement of catheters along the palmar nerves in the standing, sedated horse was recently developed and provides a method for repeated or continuous perineural administration of low concentrated local anesthetic solutions (e.g. bupivacaine or ropivacaine $0.125-0.25 \%$ ) over a period of multiple days. ${ }^{148,149}$ The therapy can 
continue for longer periods by exchange catheters every 4-8 days. With this technique significant pain relief can be obtained in horses refractory to systemic analgesic therapy and therefore suffering from unrelenting pain during a period of early or active chronic laminitis. ${ }^{149}$ The technique offers the advantage of titrating the analgesic effect by adjusting the concentration of the local anesthetic solution and/or the rate of drug administration to a desired level of comfort without causing complete sensory blockade. The CPNB catheters can also be placed more proximal on the limb in close proximity of the ulnar and median nerves. ${ }^{150}$ This technique may serve as an alternative for providing significant reduction of pain perception in the distal forelimb. ${ }^{150}$ However, the use of either CPNB technique in the acute phase of laminitis is controversial and warrants further clinical study. A pronounced nociceptive blockade of the affected limb will allow the horse to increase the load on the foot and potentially exacerbate the disruption of the lamellar dermal-epidermal bond.

In horses experiencing severe pain due to chronic laminitis in their hindlimb(s) caudal epidural administration of analgesics such as opioids (e.g. morphine 0.1-0.2 mg/kg), $\alpha_{2}$ agonists (e.g. xylazine $0.17 \mathrm{mg} / \mathrm{kg}$; detomidine $20-30 \mu \mathrm{g} / \mathrm{kg}$ ) or a combination thereof with or without low (i.e. motor function not compromising) doses of local anesthetic (e.g. bupivacaine or ropivacaine 0.125 $0.25 \%$ ) provides long-term pain control. ${ }^{151}$ To allow repeated drug administration it is recommended to place an epidural catheter. ${ }^{151}$ Medications may be administered in form of intermittent boluses $(15-30 \mathrm{~mL})$ or as an infusion $(0.5-3.0 \mathrm{~mL} / \mathrm{hr})$. As with the CPNB techniques similar restrictions apply to the use of epidural analgesia in the acute phase of laminitis.

\section{SUMMARY}

Managing pain in horses with chronic laminitis is often challenging as the disease process triggers a cascade of events that turns the somatosensory nervous system into a state of nociceptive hyperactivity with abnormal impulse processing often unresponsive to classic anti-inflammatory drug treatment. Appreciating this maladaptive pain state as the product of complex neuropathological processes affecting both the peripheral and central somatosensory nervous system is crucial when devising a treatment plan for horses afflicted by chronic laminitis. Effective analgesia calls from the outset for a multi-modal approach that involves a combination of agents with different pharmacological mechanisms of action targeting different sites within the nociceptive system and requires both systemic and local/regional drug administration. A pain grading system should be applied that allows for objective pain assessment and close monitoring of changes in nociception as a result of disease progress and/or response to analgesic therapy. 


\section{REFERENCES}

1. Moore RM. Laminitis vision: $20 / 20$ by 2020 . In: Proceedings of the Fifth International Equine Conference on Laminitis and Diseases of the Foot. Palm Beach, FL, USA: 2009, p. 15-20.

2. Orsini J, Galantino-Homer H, Pollitt CC. Laminitis in horses: through the lens of systems theory. J Equine Vet Sci 2009;29(2):105-14.

3. Hood DM. Laminitis in the horse. Vet Clin North Am Equine Pract 1999;15(2):287-94.

4. Pollitt CC. Equine laminitis. Clin Tech Equine Pract 2004;3(1):34-44.

5. Rendle D. Equine laminitis. 1. Management in the acute stage. In Practice 2006;28:43443.

6. Fontaine GL, Belknap JK, Allen D, et al. Expression of interleukin-1 $\beta$ in the digital laminae of horses in the prodromal stage of experimentally induced laminitis. Am J Vet Res 2001;62(5):714-20.

7. Waguespack RW, Cochran A, Belknap JK. Expression of the cyclooxygenase isoforms in the prodromal stage of black walnut-induced laminitis in horses Am J Vet Res 2004;65(12):1724-29.

8. Blikslager AT, Yin CL, Cochran AM, et al. Cyclooxygenase expression in the early stages of equine laminitis: a cytologic study. J Vet Intern Med 2006;20(5):1191-6.

9. Noschka E, Moore JN, Peroni JF, et al. Thromboxane and isoprostanes as inflammatory and vasoactive mediators in black walnut heartwood extract induced equine laminitis. Vet Immunol Immunopathol 2009;129(3/4):200-10.

10. Pollitt CC. Basement membrane pathology: a feature of acute equine laminitis. Equine vet J 1996;28(1):38-46.

11. Pollitt CC, Daradka M. Equine laminitis basement membrane pathology: loss of type IV collagen, type VII collagen and laminin immunostaining. Equine vet J 1998 Suppl 26:13944.

12. Johnson PJ, Tyagi SC, Katwa LC, et al. Activation of extracellular matrix metalloproteinases in equine laminitis. Vet Rec 199814(2):392-6.

13. Johnson PJ, Kreeger JM, Keeler M, et al. Serum markers of lamellar basement membrane degradation and lamellar histopathological changes in horses affected with laminitis. Equine vet J 2000;32(6):462-8. 
14. Kyaw-Tanner M, Pollitt CC. Equine laminitis: increased transcription of matrix metalloproteinase-2 (MMP-2) occurs during the developmental phase. Equine vet $\mathrm{J}$ 2004;36(3):221-5.

15. Yaksh TL. Pain Management I: Basic mechanisms in pain processing. In: Proceedings of the Fifth International Equine Conference on Laminitis and Diseases of the Foot. Palm Beach, FL, USA: 2009, p. 84-5.

16. Yaksh TL. Pain Management II: Current thinking on the mechanisms underlying laminitic pain. In: Proceedings of the Fifth International Equine Conference on Laminitis and Diseases of the Foot. Palm Beach, FL, USA: 2009, p. 86-8.

17. Bowker RM, Brewer AM, Vex KBA, et al. Sensory receptors in the equine foot. Am J Vet Res 1993;54(11):1840-4.

18. Van Wulfen KK, Bowker RM. Evaluation of tachykinins and their receptors to determine sensory innervation in the dorsal hoof wall and insertion of the distal sesamoidean impar ligament and deep digital flexor tendon on the distal phalanx in healthy feet of horses. Am J Vet Res 2002;63(2):222-8.

19. Buda S, Budras KD. Segment specific nerve supply of the equine hoof. Pferdeheilkunde 2005;21(4):280-4.

20. Molyneux GS, Haller CJ, Mogg K, et al. The structure, innervation and location of arteriovenous anastomoses in the equine foot. Equine vet J 1994;26(4):305-12.

21. Morgan SJ, Grosenbaugh DA, Hood DM. The pathophysiology of chronic laminitis. Vet Clin North Am Equine Pract 1999;15(2):395-417.

22. Giordano J. The neurobiology of pain. In: Weiner RS, ed. Pain management: a practical guide for clinicians, $6^{\text {th }}$ edition. Boca Raton, FL, CRC Press; 2001. p. 1089-1100.

23. Orsini JA, Galantino-Homer H, Pollitt CC. Hot topics at the fourth international equine conference on laminitis and diseases of the foot. In: Large animal proceedings of the North American Veterinary Conference. Orlando, Florida, USA: 2009, p. 216-7.

24. Jones E, Viñuela-Fernandez I, Eager RA, et al. Neuropathic changes in equine laminitis pain. Pain 2007;132:321-31.

25. Owens JG, Kamerling SG, Keowen ML. Eicosanoid concentrations in digital venous blood from horses with chronic laminitis. Am J Vet Res 1995;56(4):507-10.

26. Moore JN, Allen D. The pathophysiology of acute laminitis. Vet Med 1996;10;936-9. 
27. Doubell TP, Mannion RJ, Wolf CJ. The dorsal horn: state dependent sensory processing, plasticity, and the generation of pain. In: Wall PD, Melzak R, editors: Textbook of pain, $4^{\text {th }}$ edition. New York, NY, USA: Churchill-Livingstone; 1999. p. 165-82.

28. Klusakova I, Dubovy P. Experimental models of peripheral neuropathic pain based on traumatic nerve injuries - an anatomical perspective. Ann Anat 2009;191(3):248-59.

29. Costigan M, Scholz J, Woolf CJ. Neuropathic pain: a maladaptive response of the nervous system to damage. Ann Rev Neurosci 2009;32:1-32.

30. Driessen B. Pain: From sign to disease. Clin Tech Equine Pract 2007;6(2):120-5.

31. Kawasaki Y, Xu ZZ, Wang X, et al. Distinct roles of matrix metalloproteases in the earlyand late-phase development of neuropathic pain. Nature Medicine 2008;14(3):331-6.

32. Driessen B, Zarucco L. Pain: From diagnosis to effective treatment. Clin Tech Equine Pract 2007;6(2):126-34.

33. Obel N. Studies on the histopathology of acute laminitis (dissertation). Uppsala, Sweden: Almqvist and Wiksells Boktryckteri AK; 1948.

34. American Association of Equine Practioners. Definition and classification of lameness. In: American Association of Equine Practioners: Guide for veterinary service and judging of equestrian events. $4^{\text {th }}$ edition. Lexington, KY, USA; 1991. p. 19.

35. Dutton DW, Lashnits KJ, Wegner K. Managing severe hoof pain in a horse using multimodal analgesia and a modified composite pain score. Equine vet Educ 2009;21:3743.

36. Aviad AD. The use of the standing force plate as a quantitative measure of equine lameness. J Equine Vet Sci 1988;8:460-2.

37. Hood DM, Wagner IP, Taylor DD, et al. Voluntary limb-load distribution in horses with acute and chronic laminitis. Am J Vet Res 2001;66(9):1393-8.

38. Hunt RJ. Diagnosing and treating chronic laminitis in horses. Vet Med 1996; 91(11):102532.

39. Brumbaugh GW, Sumano Lopez H, Hoyos Sepulveda, MLH. The pharmacologic basis for the treatment of developmental and acute laminitis. Vet Clin North Am Equine Pract 1999; 15(2):345-62.

40. Sumano Lopez H, Hoyos Sepulveda ML, Brumbaugh GW. Pharmacologic and alternative therapies for the horse with chronic laminitis. Vet Clin North Am Equine Pract;15(2):495516.

41. Parks AH. Treatment of acute laminitis. Equine vet Educ 2003;15(5):273-280. 
42. Parks A, O’Grady SE. Chronic laminitis: current treatment strategies. Vet Clin North Am Equine Pract 2003;19(2):393-416.

43. Belknap JK. Treatment of the acute laminitis case. In: Large animal proceedings of the North American Veterinary Conference. Orlando, Florida, USA: 2006, p. 76-8.

44. Belknap JK. Treatment of the chronic laminitis case. In: Large animal proceedings of the North American Veterinary Conference. Orlando, Florida, USA: 2006, p. 79-80.

45. Piccot-Crezollet C, Olive J, Cadore JL. Diagnostic and therapeutic approaches in the face of acute laminitis in horses. Le Nouveau Praticien Veterinaire - Equine 2008;5(17):17-23.

46. Moore RM. Evidence-based treatment for laminitis - what works? J Equine Vet Sci 2008;28(3):176-9.

47. Moyer W, Schumacher J, Schumacher J, et al. Are drugs effective treatment for horses with acute laminitis? In: Proceedings of the $54^{\text {th }}$ Annual Convention of the American Association of Equine Practioners, San Diego, California, USA: 2008, p. 337-40.

48. Divers TJ. Medical treatment of acute laminitis. In: Large animal proceedings of the North American Veterinary Conference. Orlando, Florida, USA: 2009, p. 174.

49. Siddall PJ, Cousins MJ. Persistent pain as a disease entity: implications for clinical management. Anesth Analg 2004;99:510-20.

50. Hansen N, Buchner F, Haller J, et al. Evaluation using hoof wall strain gauges of a therapeutic shoe and a hoof cast with a heel wedge as potential supportive therapy for horses with laminitis. Vet Surg 2005;34:630-6.

51. Morrison S. Rehabilitating the laminitic foot. In: Large animal proceedings of the North American Veterinary Conference. Orlando, Florida, USA: 2008, p. 186-9.

52. Hunt RJ, Allen D, Baxter GM, et al. Mid-metacarpal deep digital flexor tenotomy in the management of refractor laminitis in horses. Vet Surg 1991;20(1)15-20.

53. Vasko KA, Spauchus A, Lowry M. Laminitis treatment with electrotherapy. Equine Pract 1986; 8(4):28-31

54. Carter DW, Renfroe JB. A novel approach to the treatment and prevention of laminitis: botulinum toxin type A for the treatment of laminitis. J Equine Vet Sci 2009;29(7):595600.

55. Galluzzi KE. Management of neuropathic pain. J Am Osteopath Assoc 2005;105(9):S129.

56. Finnerup NB, Otto M, McQuay HJ, et al. Algorithm for neuropathic pain treatment: An evidence based proposal. Pain 2005;118(3):289-305. 
57. Dworkin RH. O'Connor AB. Backonja M, et al. Pharmacologic management of neuropathic pain: evidence-based recommendations. Pain 2007;132(3):237-51.

58. O'Connor AB, Dworkin RH. Treatment of neuropathic pain: an overview of recent guidelines. Am J Med 2009;122(10 Suppl):S22-32.

59. McGeeney BE. Pharmacological management of neuropathic pain in older adults: an update on peripherally and centrally acting agents. J Pain Symptom Manage 2009;38(2 Suppl):S15-27.

60. Clark JO, Clark TP. Analgesia. Vet Clin Equine 1999;15(3):705-23.

61. Pollitt CC. Medical therapy of laminitis. In: Ross MW, Dyson SJ, editors: Diagnosis and management of lameness in the horse. St. Louis, Missouri, USA: Saunders; 2003. p. 32932.

62. Rouzer CA, Marnett LJ. Structural and functional differences between cyclooxygenases: fatty acid oxygenases with a critical role in cell signaling, Biochem Biophys Res Commun 2005;338(1):34-44.

63. Yaksh TL, Dirig DM, Conway CM, et al. The acute antihyperalgesic action of nonsteroidal, anti-inflammatory drugs and release of spinal prostaglandin $\mathrm{E}_{2}$ is mediated by the inhibition of constitutive spinal cyclooxygenase-2 (COX-2) but not COX-1. J Neurosci 2001;21(6):5847-53.

64. Urdaneta A, Siso A, Urdaneta B, et al. Lack of correlation between the central antinociceptive and peripheral anti-inflammatory effects of selective COX-2 inhibitor parecoxib. Brain Res Bull 2009;80(1-2):56-61.

65. Simon LS. Biology and toxic effects of nonsteroidal anti-inflammatory drugs. Curr Opin Rheumatol 1998;10(3):153-8.

66. Blikslager A. Role of NSAIDs in the management of pain in horses. In: Proceedings of the American Association of Equine Practioners-Focus Meeting, Raleigh, North Carolina, USA: 2009, p. 218-23.

67. Divers TJ. COX inhibitors: Making the best choice for the laminitic case. J Equine Vet Sci 2008;28(6):367-9.

68. Cryer B, Feldman M. Cyclooxygenase-1 and cyclooxygenase-2 selectivity of widely used nonsteroidal anti-inflammatory drugs. Am J Med 1998;104(5):413-21.

69. Owens JG, Kamerling SG, Stanton SR, et al. Effects of ketoprofen and phenylbutazone on chronic hoof pain and lameness in the horse. Equine Vet J 1995;27(4):296-300. 
70. Ossipov MH, Jerussi TP, Ren K, et al. Differential effects of spinal (R)-ketoprofen and (S)-ketoprofen against signs of neuropathic pain and tonic nociception: evidence for a novel mechanism of action of (R)-ketoprofen against tactile allodynia. Pain 2000; 87(2):193-9.

71. Diaz-Reval MI, Ventura-Martinez R, Deciga-Campos M, et al. Evidence for a central mechanism of action of S-(+)-ketoprofen. Eur J Pharmacol 2004;483(2-3):241-8.

72. Whay HR, Webster AJF, Waterman-Pearson AE. Role of ketoprofen in the modulation of hyperalgesia associated with lameness in dairy cattle. Vet Rec 2005;157(23):729-733.

73. Moses VS, Bertone AL. Nonsteroidal anti-inflammatory drugs. Vet Clin North Am Equine Pract 2002;18(1):21-37.

74. Snow DH, Douglas TA, Thompson H, et al. Phenylbutazone toxicosis in equidae: a biochemical and pathophysiological study. Am J Vet Res 1981;42(10):1754-9.

75. Doucet MY, Bertone AL, Hendrickson D, et al. Comparison of efficacy and safety of paste formulations of firocoxib and phenylbutazone in horses with naturally occurring osteoarthritis. J Am Vet Med Assoc 2008;232(1):91-7.

76. MacAllister CG, Morgan SJ, Borne AT, et al. Comparison of adverse effects of phenylbutazone, flunixin meglumine, and ketoprofen in horses. J Am Vet Med Assoc 1993;202(1):71-7.

77. Bennett RC, Steffey EP. Use of opioids for pain and anesthetic management in horses. Vet Clin North Am Equine Pract 2002;18(1):46-60.

78. Driessen B. Pain: Systemic and local/regional drug therapy. Clin Tech Equine Pract 2007;6(2):135-44.

79. Valverde A, Gunkel C. Pain management in horses and farm animals. J Vet Emerg Crit Care 2005;15(4):295-307.

80. Angst MS. Opioid-induced Hyperalgesia: A Qualitative Systematic Review. Anesthesiology 2006;104(3):570-87.

81. Chu LF, Angst MS, Clark D. Opioid-induced hyperalgesia in humans: molecular mechanisms and clinical considerations. Clin J Pain 2008;24(6):479-96.

82. Silverman SM. Opioid induced hyperalgesia: clinical implications for the pain practitioner. Pain Physician 2009;12(3):679-84.

83. Fishbain DAA. Do opioids induce hyperalgesia in humans? An evidence-based structured review. Pain Med 2009;10(5):829-39. 
84. Sellon DC, Monroe VL, Roberts MC, et al. Pharmacokinetics and adverse effects of butorphanol administered by single intravenous injection or continuous intravenous infusion in horses. Am J Vet Res 2001(2);48:183-9.

85. Sellon DC, Roberts MC, Blikslager AT, et al. Effects of continuous rate intravenous infusion of butorphanol on physiologic and outcome variables in horses after celiotomy. $\mathrm{J}$ Vet Intern Med 2004;18(4):555-63.

86. Wegner K, Franklin RP, Long MT, et al. How to use fentanyl transdermal patches for analgesia in horses. In: Proceedings of the $48^{\text {th }}$ Annual Convention of the American Association of Equine Practitioners, Orlando, Florida, USA: 2002, p. 291-4.

87. Thomasy SM, Slovis N, Maxwell LK, et al. Transdermal fentanyl combined with nonsteroidal anti-inflammatory drugs for analgesia in horses. $\mathrm{J}$ Vet Intern Med 2004;18(4):550-4.

88. Orsini JA, Moate PJ, Kuersten $\mathrm{K}$, et al. Pharmacokinetics of fentanyl delivered transdermally in healthy adult horses - variability among horses and its clinical implications. J vet Pharmacol Therap 2006;29(6):539-546.

89. Carregaro AB, Luna SP, Mataqueiro MI, et al. Effects of buprenorphine on nociception and spontaneous locomotor activity in horses. Am J Vet Res 2007;68(3):246-50.

90. Walker AF. Sublingual administration of buprenorphine for long-term analgesia in the horse. Vet Rec 2007;160(23):808-9.

91. Mao J, Chen LL. Systemic lidocaine for neuropathic pain relief. Pain 2000;87(1):7-17.

92. Malone E, Graham L. Management of gastrointestinal pain. Vet Clin Equine Pract 2002;18(1):133-158.

93. Driessen B. Intravenous lidocaine infusion in balanced anaesthesia for abdominal surgery: update and clinical experiences. Pferdeheilkunde 2005;21(2):133-141.

94. Murrell JC, White KL, Johnson CB, et al. Investigation of the EEG effects of intravenous lidocaine during halothane anaesthesia in ponies. Vet Anaesth Analg 2005;32(4):212-221.

95. Robertson SA, Sanchez LC, Merritt AM, et al. Effect of systemic lidocaine on visceral and somatic nociception in conscious horses. Equine vet J 2005;37(2):122-7.

96. Feary DJ, Mama KR, Wagner AE, et al: Influence of general anaesthesia on pharmacokinetics of intravenous lidocaine infusion in horses. Am $J$ Vet Res 2005;66(4):574-580. 
97. Gottrup H, Bach FW, Juhl G, et al. Differential effect of ketamine and lidocaine on spontaneous and mechanical evoked pain in patients with nerve injury pain. Anesthesiology 2006;104(3):527-36.

98. Gormsen L, Finnerup NB, Almqvist PM, et al. The efficacy of the AMPA receptor antagonist NS1209 and lidocaine in nerve injury pain: a randomized, double-blind, placebo-controlled, three-way crossover study. Anesth Analg 2009;108(4):1311-9.

99. Meyer GA, Lin HC, Hanson RR, et al. Effects of intravenous lidocaine overdose on cardiac electrical activity and blood pressure in the horse. Equine vet J 2001;33(5):434-7.

100. De Solis CN, McKenzie HC $3^{\text {rd }}$. Serum concentrations of lidocaine and its metabolites MEGX and GX during and after prolonged intravenous infusion of lidocaine in horses after colic surgery. J Equine Vet Sci 2007;27(9):398-404.

101. Dickey EJ, McKenzie HC $3^{\text {rd }}$, Brown KA, et al. Serum concentrations of lidocaine and its metabolites after prolonged infusion in healthy horses. Equine vet J 2008;40(4):348-52.

102. Woolf CJ, Wiesenfeld-Hallin Z. The systemic administration of local anaesthetics produces a selective depression of $\mathrm{C}$-afferent fibre evoked activity in the spinal cord. Pain 1985;23(4):361-74.

103. Ness T. Intravenous lidocaine inhibits visceral nociceptive reflexes and spinal neurons in the rat. Anesthesiology 2000;92(6):1685-91.

104. Lauretti GR. Mechanisms of analgesia of intravenous lidocaine. Revista Brasileira de Anestesiologia 2008;58(3):280-6.

105. Abram SE. Yaksh TL. Systemic lidocaine blocks nerve injury-induced hyperalgesia and nociceptor-driven spinal sensitization in the rat. Anesthesiology 1994;80(2):383-91.

106. Koppert W, Dern SK, Sittl R, et al. New model of electrically evoked pain and hyperalgesia in human skin: the effects of intravenous alfentanil, $\mathrm{S}(+)$-ketamine, and lidocaine. Anesthesiology 2001;95(2):395-402.

107. Attal N, Rouaud J, Brasseur L, et al. Systemic lidocaine in pain due to peripheral nerve injury and predictors of response. Neurology 2004;62(2):218-25.

108. Taniguchi T, Shibata K, Yamamoto K, et al. Lidocaine attenuates the hypotensive and inflammatory responses to endotoxemia in rabbits. Crit Care Med 1996;24(4):642-6.

109. Hollmann MW, Durieux ME. Local anesthetics and the inflammatory response: a new therapeutic indication? Anesthesiology 2000;93(3):858-75. 
110. Brianceau P, Chevalier H, Karas A, et al. Intravenous lidocaine and small-intestinal size, abdominal fluid, and outcome after colic surgery in horses. J Vet Intern Med 2002;16():736-41.

111. Cook VL, Jones Shults J, McDowell MR et al. Attenuation of ischaemic injury in the equine jejunum by administration of systemic lidocaine. Equine vet J 2008;40(4):353-7.

112. Cook VL, Jones Shults J, McDowell MR et al. Anti-inflammatory effects of intravenously administered lidocaine hydrochloride on ischemia-injured jejunum in horses. Am J Vet Res 2009;70(10):1259-68.

113. Cook VL, Neuder LE, Blikslager AT, et al. The effect of lidocaine on in vitro adhesion and migration of equine neutrophils. Vet Immunol Immunopathol 2009;129(1-2):137-42.

114. Taylor CP. The biology and pharmacology of calcium channel $\alpha_{2}-\delta$ proteins. CNS Drug Rev 2004;10(2):183-8.

115. Dixit RK, Bhargava VK. Neurotransmitter mechanisms in gabapentin antinociception. Pharmacol 2002;65(4):198-203

116. Sills GJ. The mechanisms of action of gabapentin and pregabalin. Curr Opin Pharmacol 2006;6:108-113.

117. Luo ZD, Chaplan SR, Higuera ES, Sorkin LS, et al. Upregulation of dorsal root ganglion $\alpha 2 \delta$ calcium channel subunit and its correlation with allodynia in spinal nerve-injured rats. J Neurosci 2001;21(6):1868-75.

118. Newton RA, Bingham S, Case PC, et al. Dorsal root ganglion neurons show increased expression of the calcium channel $\alpha 2 \delta$ - 1 subunit following partial sciatic nerve injury. Mol Brain Res 2001;95(1-2):1-8.

119. Maneuf YP, Luo ZD, Lee K. $\alpha 2 \delta$ and the mechanism of action of gabapentin in the treatment of pain. Semin Cell Dev Biol 2006;17(5):565-70.

120. Harding LM, Kristensen JD, Baranowski AP. Differential effects of neuropathic analgesics on wind-up-like pain and somatosensory function in healthy volunteers. Clin $\mathrm{J}$ Pain 2005;21(2):127-32.

121. Arendt-Nielsen L, Brøndum Frøkjær J, Staahl C, et al. Effects of gabapentin on experimental somatic pain and temporal summation. Reg Anesth Pain Med (2007);32(5), $382-8$.

122. Gilron I. Gabapentin and pregabalin for chronic neuropathic and early postsurgical pain: current evidence and future directions. Curr Opin Anesthesiol 2007; 20:456-72. 
123. Ripamonti C, Dickerson ED. Strategies for the treatment of cancer pain in the new millennium. Drugs 2001;61(7):955-77.

124. Van Elstraete AC, Sitbon P, Mazoit JX, et al. Gabapentin prevents delayed and longlasting hyperalgesia induced by fentanyl in rats. Anesthesiology 2008;108(3):484-94.

125. Davis JL, Posner LP, Elce Y. Gabapentin for the treatment of neuropathic pain in a pregnant horse. J Am Vet Med Assoc 2007;231(5):755-8.

126. Dirikolu L, Dafalla A, Ely KJ, et al. Pharmacokinetics of gabapentin in horses. J vet Pharmacol Therap 2008;31(2):175-7.

127. Terry R, McDonnell SM, van Eps AW, et al. Pharmacokinetic profile and behavioral effects of gabapentin in the horse. J vet Pharmacol Therap 2010: in print

128. Eckhardt K, Ammon S, Hofmann U, et al. Gabapentin enhances the analgesic effect of morphine in healthy volunteers. Anesth Analg 2000;91(1):185-91.

129. Rison RA, Stanton PK: Long-term potentiation and N-methyl-D-aspartate receptors: foundations of memory and neurologic disease? Neurosci Biobehav Rev 1995;19(4):53352.

130. Mori H, Mishina M. Structure and function of the NMDA receptor channel. Neuropharmacol 1995;34(10):1219-37.

131. Orser BA, Pennefather PS, MacDonald JF. Multiple mechanisms of ketamine blockade of N-methyl-D-aspartate receptors. Anesthesiology 1997;86(4):903-17.

132. Wong CS, Cherng CH, Ho ST. Clinical applications of excitatory amino acid antagonists in pain management. Acta Anaesthesiol Sin 1995;33(4):227-32.

133. Schmid RL, Sandler AN, Katz J. Use and efficacy of low-dose ketamine in the management of acute postoperative pain: a review of current techniques and outcomes. Pain 1999;82(2):111-25.

134. Hocking G, Cousins MJ. Ketamine in chronic pain management: an evidence-based review. Anesth Analg 2003;97(6):1730-9.

135. Richebe $\mathrm{P}$, Rivat C, Rivalan B. Low doses ketamine: antihyperalgesic drug, non-analgesic. Ann Fr Anesth Reanim 2005;24(11-12):1349-59.

136. Strigo IA, Duncan GH, Bushnell C, et al. The effects of racemic ketamine on painful stimulation of skin and viscera in human subjects. Pain 2005;113(3):255-64.

137. De Kock MF, Lavand'homme PM. The clinical role of NMDA receptor antagonists for the treatment of postoperative pain. Best Pract Res Clin Anaesthesiol 2007;21(1):85-98. 
138. Visser E, Schug SA. The role of ketamine in pain management. Biomed Pharmacother 2006;60(7):341-8.

139. Fielding CL, Brumbaugh GW, Matthews NS, et al. Pharmacokinetics and clinical effects of a subanesthetic continuous rate infusion of ketamine in awake horses. Am J Vet Res 2006;67(9):1484-90.

140. Lankveld DPK, Driessen B, Soma LR, et al. Pharmacodynamic effects and pharmacokinetic profile of a long-term continuous rate infusion of racemic ketamine in healthy conscious horses. J Vet Pharmacol Therap 2006;29(6):477-88.

141. Levionnois OL, Menge M, Thormann W. Effect of ketamine on the limb withdrawal reflex evoked by transcutaneous electrical stimulation in ponies anaesthetised with isoflurane. Vet J, In Press, Corrected Proof, Available online 12 September 2009.

142. Matthews NS, Fielding CI, Swinebroad E. How to use a ketamine constant rate infusion in horses for analgesia. In: Proceedings of the $50^{\text {th }}$ Annual Convention of the American Association of Equine Practitioners, Denver, Colorado, USA: 2004, p. 1431.

143. Suter MR, Papaloizos M, Berde CB, et al. Development of neuropathic pain in the rat spared nerve injury model is not prevented by a peripheral nerve block. Anesthesiology 2003;99(6):1402-8.

144. Xie W, Strong JA, Meij JT, et al. Neuropathic pain: early spontaneous afferent activity is the trigger. Pain 2005;116(3):243-56.

145. Reuben SS, Buvanendran A. Preventing the development of chronic pain after orthopaedic surgery with preventive multimodal analgesic techniques. J Bone Joint Surg Am 2007 ;89(6):1343-58.

146. Beloeil H, Gentili M, Benhamou D, et al. The effect of a peripheral block on inflammation-induced prostaglandin $\mathrm{E}_{2}$ and cyclooxygenase expression in rats. Anesth Analg 2009;109(3):943-50.

147. Estebe JP, Gentili ME, Le Corre P, et al. Sciatic nerve block with bupivacaine-loaded microspheres prevents hyperalgesia in an inflammatory animal model. Can J Anaesth 2002;49(7):690-3.

148. Driessen B, Scandella M, Zarucco L. Development of a technique for continuous perineural blockade of the palmar nerves in the distal equine thoracic limb. Vet Anaesth Analg 2008;35:432-448. 
149. Zarucco L, Driessen B, Scandella M, et al. Continuous perineural block of the palmar nerves: A new technique for pain relief in the distal equine forelimb. Clin Tech Equine Pract 2007;6(2):154-164.

150. Zarucco L, Scandella M, Seco O, et al. Ultrasound-guided technique for continuous ulnar and median nerve blockade in the horse. Vet Surg 2008;37(6):E34.

151. Natalini CC, Driessen B. Epidural and spinal anesthesia and analgesia in the equine. Clin Tech Equine Pract 2007;6(2):144-153

152. Leise BS, Fugler LA, Stokes AM, et al. Effects of intramuscular administration of acepromazine on palmar digital blood flow, palmar digital arterial pressure, transverse facial arterial pressure, and packed cell volume in clinically healthy, conscious horses. Vet Surg 2007;36(8):717-723. 
Table 1: Modified composite pain score (MCPS). ${ }^{35}$

\section{Dynamic score: Modified Obel Grading System}

\begin{tabular}{|l|l|}
\hline Grade & Descriptor \\
\hline 1 & Frequent shifting of weight between the feet with no discernible lameness at the walk. \\
\hline 2 & Does not resist having a foreleg lifted, is not reluctant to walk, but does show lameness at \\
\hline 3 & Resists having a foreleg lifted and is reluctant to walk. \\
\hline 4 & Walks only if forced. \\
\hline
\end{tabular}

\section{Static score: Modified from Glasgow composite scale}

Score Descriptor

$1 \quad$ No pain or distress: normal behaviour.

$2 \quad$ Mild pain: irritable, restless, decreased appetite.

$3 \quad$ Mild pain: 2 plus resists handling.

$4 \quad$ Mild-moderate pain: 3 plus standing in back of stall or with back to stall door.

$5 \quad$ Moderate pain: 4 plus camped-out legs, increased digital pulses.

6 Moderate-severe pain: 5 plus frequent recumbency, HR $>44$ beats/min, and/or RR $>24$ breaths/min

$7 \quad$ Moderate-severe pain: 6 plus sweating, muscle fasciculation, head-tossing.

$8 \quad$ Severe pain: 7 plus unwilling to move.

$9 \quad$ Severe-extreme pain: 8 plus not weight bearing when standing.

10 Extreme pain: 9 or entirely recumbent, bordering on agonal. 
Table 2: Sensory symptoms and signs associated with neuropathic pain. ${ }^{55}$

\begin{tabular}{|ll|}
\hline Symptom or sign & Description \\
\hline Allodynia & $\begin{array}{l}\text { Pain due to non-noxious stimuli (e.g. light touch) when applied to the affected } \\
\text { area. May be mechanical (eg, caused by light pressure), dynamic (caused by non- } \\
\text { painful movement of a stimulus), or thermal (caused by non-painful warm, or } \\
\text { cool stimulus). }\end{array}$ \\
\hline Anesthesia & $\begin{array}{l}\text { Loss of normal sensation to the affected region. } \\
\text { Hyperalgesia }\end{array}$ \\
\hline region. \\
\hline Hyperpathia & Delayed and explosive response to a noxious stimulus applied to the affected \\
\hline Referred pain & Occurs in a region remote from the source of stimulation. \\
\hline
\end{tabular}


Table 3: Doses of commonly used non-steroidal antiinflammatory drugs (NSAIDs) in horses.

\begin{tabular}{|c|c|c|c|}
\hline $\begin{array}{l}\text { Non-Steroidal Anti- } \\
\text { Inflammatory Drug }\end{array}$ & $\begin{array}{l}\text { Dose, route } \& \text { interval of drug } \\
\text { administration* }\end{array}$ & Comments & References \\
\hline \multicolumn{4}{|c|}{ Non-selective COX-1 \& 2 inhibitors } \\
\hline Phenylbutazone & $\begin{array}{l}2.2-4.4 \text { (up to } 6 \text { ) } \mathrm{mg} / \mathrm{kg} \text { IV/PO } \\
\text { SID-BID }\end{array}$ & $\begin{array}{l}\text { Highest toxicity } \\
\text { among NSAIDs }\end{array}$ & $\begin{array}{l}43,44,47,55 \\
62,64,68,73\end{array}$ \\
\hline Flunixine meglumine & $1.1 \mathrm{mg} / \mathrm{kg}$ IV/PO SID-BID & $\begin{array}{l}\text { Cases of muscle } \\
\text { necrosis reported } \\
\text { with IM injection }\end{array}$ & $47,68,73$ \\
\hline Ketoprofen & 2.2-3.6 mg/kg IV/IM SID-QID & $\begin{array}{l}\text { Only parenteral } \\
\text { administration }\end{array}$ & $55,64,68,73$ \\
\hline Vedaprofen & $1-2 \mathrm{mg} / \mathrm{kg}$ IV/PO SID-BID & Limited experience & 73,74 \\
\hline Eltenac & $0.5-1 \mathrm{mg} / \mathrm{kg}$ IV SID & Limited experience & $68,73,74$ \\
\hline Naproxen & $\begin{array}{l}5 \mathrm{mg} / \mathrm{kg} \mathrm{IV} \\
10 \mathrm{mg} / \mathrm{kg} \text { PO SID }\end{array}$ & $\begin{array}{l}\text { Initially slow IV } \\
\text { bolus, then PO }\end{array}$ & 73 \\
\hline \multicolumn{4}{|c|}{ Preferential or selective COX-2 inhibitors } \\
\hline Meloxicam & $0.6 \mathrm{mg} / \mathrm{kg}$ IV/PO SID-BID & & $68,73,74$ \\
\hline Etodolac & $10-20 \mathrm{mg} / \mathrm{kg}$ IV/PO SID-BID & Limited experience & 68,73 \\
\hline Firocoxib & $0.1 \mathrm{mg} / \mathrm{kg}$ PO SID & $\begin{array}{l}\text { May require } 0.3 \\
\mathrm{mg} / \mathrm{kg} \text { on } 1 \mathrm{st} \text { day of } \\
\text { administration }\end{array}$ & $69,70,73$ \\
\hline
\end{tabular}

Routes and intervals of drug administration: IV, intravenous; IM, intramuscular; PO, per os; SID, once daily; BID, twice daily; TID, three times daily. *Caution: More rapid metabolism and elimination of most NSAIDs in mules and donkeys may require more frequent dosing. ${ }^{62}$ 
Table 4: Doses of opioids and co-administered sedatives in horses.

\begin{tabular}{|c|c|c|}
\hline Drug & Dose, route $\&$ interval of drug administration & References \\
\hline \multicolumn{3}{|c|}{ Opioids } \\
\hline Morphine & $0.1-0.2 \mathrm{mg} / \mathrm{kg} \mathrm{IV} / \mathrm{IM}$ every $4-6 \mathrm{hrs}$ & 73,74 \\
\hline Methadone & $0.1-0.2 \mathrm{mg} / \mathrm{kg} \mathrm{IV} / \mathrm{IM}$ every $4-6 \mathrm{hrs}$ & 73,74 \\
\hline Butorphanol & $\begin{array}{l}0.01-0.4 \mathrm{mg} / \mathrm{kg} \mathrm{IV} \text {, IM every } 2-4 \mathrm{hrs}^{1} \\
\text { Bolus of } 18 \mu \mathrm{g} / \mathrm{kg} \text { bolus followed by IV CRI at } 13-24 \mu \mathrm{g} \bullet \mathrm{kg}^{-1} \bullet \mathrm{hr}^{-} \\
1\end{array}$ & $\begin{array}{l}55,72,73,74, \\
79,80\end{array}$ \\
\hline Buprenorphine & $\begin{array}{l}5-20 \mu \mathrm{g} / \mathrm{kg} \text { IV/IM TID } \\
6 \mu \mathrm{g} / \mathrm{kg} \text { sublingual BID }\end{array}$ & $73,84,85$ \\
\hline Fentanyl & 2-3 $10 \mathrm{mg}(100 \mu \mathrm{g} / \mathrm{hr})$ patches to be changed every 3 days & $81,82,83$ \\
\hline \multicolumn{3}{|c|}{ Co-administered phenothiazine and/or $\alpha_{2}$ agonist sedative/analgesic } \\
\hline Acepromazine $^{3}$ & $\begin{array}{l}0.01-0.08 \mathrm{mg} / \mathrm{kg} \text { IV } / \mathrm{IM} / \mathrm{SC} \text { BID/TID or } \\
\mathrm{CRI} \text { at } 2-4 \mu \mathrm{g} \bullet \mathrm{kg}^{-1} \bullet \mathrm{hr}^{-1}\end{array}$ & $41,47,48$ \\
\hline Detomidine & $\begin{array}{l}\text { 10-40 } \mu \mathrm{g} / \mathrm{kg} \text { IM/IV every 2-4 hrs } \\
\text { Bolus }{ }^{2} \text { of } 5-10 \mu \mathrm{g} / \mathrm{kg} \text { IV followed by CRI at } 24-36 \mu \mathrm{g} \bullet \mathrm{kg}^{-1} \\
\text { - } \mathrm{hr}^{-1}\end{array}$ & $32,73,74$ \\
\hline Medetomidine & $\begin{array}{l}\text { 5-7 } \mu \mathrm{g} / \mathrm{kg} \text { IM/IV every 2-4 hrs } \\
\text { Bolus }{ }^{2} \text { of 3-7 } \mu \mathrm{g} / \mathrm{kg} \text { IV followed by CRI at } 1.5-3.6 \mu \mathrm{g} \bullet \mathrm{kg}^{-1} \\
\bullet \mathrm{hr}^{-1}\end{array}$ & $32,73,74$ \\
\hline Dexmedetomidine & $\begin{array}{l}\text { Bolus }^{2} \text { of } 1.5-3.0 \mu \mathrm{g} / \mathrm{kg} \text { IV followed by CRI at } 0.75-1.8 \mu \mathrm{g} \bullet \mathrm{kg}^{-} \\
{ }^{-} \cdot \mathrm{hr}^{-1}\end{array}$ & \\
\hline
\end{tabular}

Routes and intervals of drug administration: IV, intravenous; IM, intramuscular; SC, subcutaneously; SID, once daily; BID, twice daily; TID, three times daily; CRI, constant rate infusion. ${ }^{1}$ Significant central excitatory 
responses to be expected from doses of $>0.05 \mathrm{mg} / \mathrm{kg}$ onwards. ${ }^{2} \mathrm{~A}$ bolus administration is optional but not always necessary, dependent on opioid dose and route of administration. ${ }^{3}$ Acepromazine has also been employed to improve perfusion of the hoof, ${ }^{41,46,483}$ even though recent studies have questioned the magnitude of such an effect. ${ }^{152}$ 


\section{Amelioration of Pain in Chronic Laminitis}

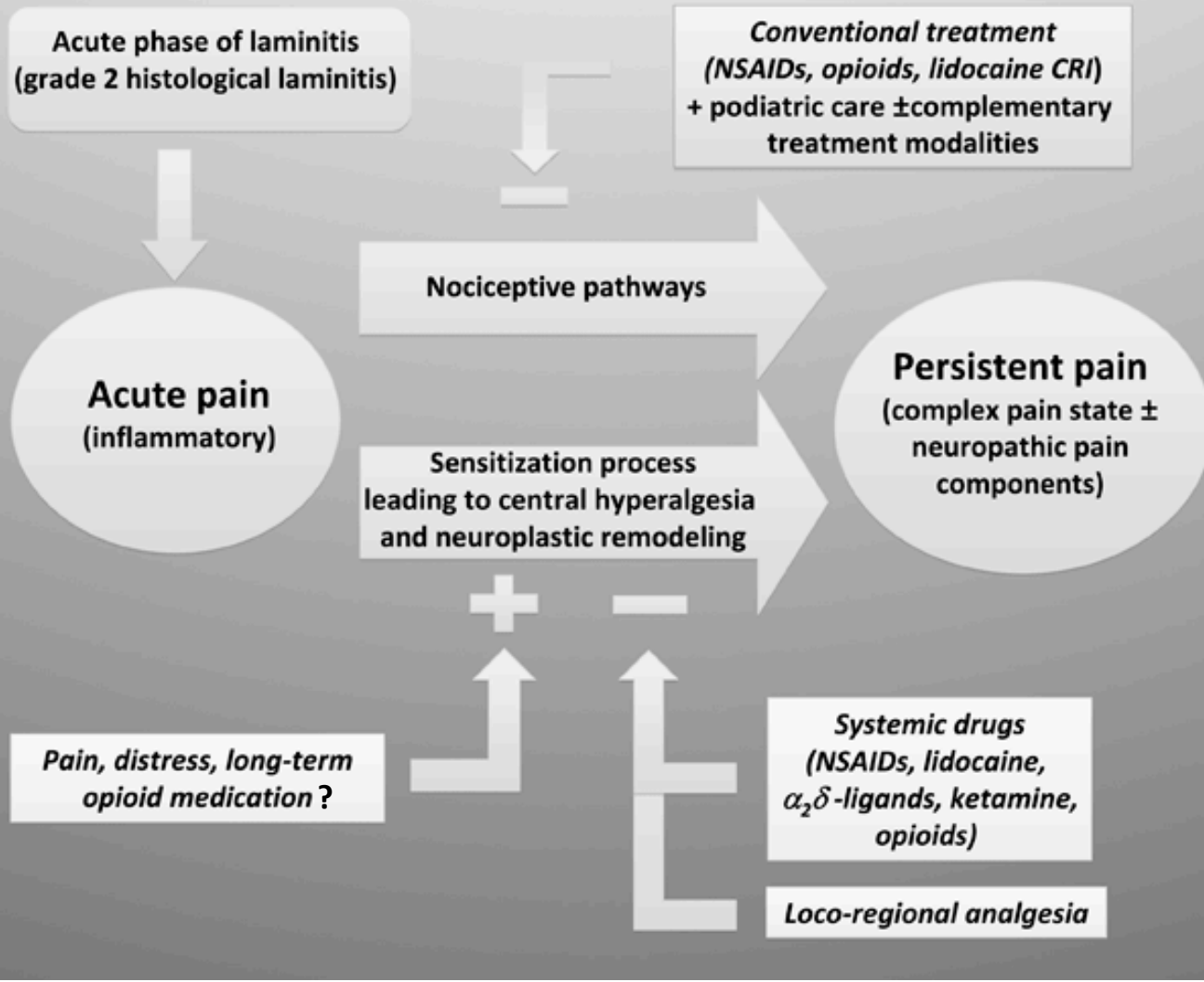

Figure 1: Multimodal approach to pain management in the horse with chronic laminitis (see text for more detail). 